\title{
O GRAFO DO ATO ANALÍTICO
}

Mônica Assunção Costa Lima

\author{
Mônica Assunção Costa \\ Lima \\ Pontifícia \\ Universidade \\ Católica de \\ Minas Gerais \\ (PUC-Minas), \\ Departamento de \\ Psicologia, Belo \\ Horizonte/MG, \\ Brasil.
}

RESUMO: Analisa-se o grafo do ato analítico apresentado por Lacan no Seminário XV, a partir do grupo matemático de Klein e da interpretação particular de Lacan da filosofia cartesiana. Apresenta-se inicialmente a leitura lacaniana do cogito cartesiano no Seminário XI, para pontuar as alterações encontradas em sua releitura efetuada em 1967. Apresenta-se o esquema de Klein, proposto pelo matemático Barbut, no qual se inspirou Lacan, e discute-se em seguida as operações nele designadas como: operação alienação, operação verdade e operação transferência. Demonstra-se como Lacan se apropriou deste esquema, relacionando-o ao percurso da análise e articulando-o sempre aos termos cartesianos encontrados no comentário sobre o cogito: ser e pensamento.

Palavras-chave: psicanálise, grafo do ato analítico, cogito cartesiano, percurso da análise.

ABSTRACT: The graph of the psychoanalytical act. The article analyzes the graph of the analytic act introduced by Lacan in his 15th Seminar from the perspective of the mathematical group of Klein and the particular Lacanian interpretation of Cartesian philosophy. Initially the article presents the Lacanian interpretation of the Cartesian cogito introduced in his 11th seminary, in order to highlight the alterations made in his second interpretation performed in 1967. We will present Klein's scheme proposed by Barbut, the mathematician, which provides the graph of the act's structure and then we will discuss the operations designated here as alienation, truth and transfer. We will demonstrate the appropriation made by Lacan of this scheme, relating it to the several steps of a psychoanalytical cure and linking it to the Cartesian terms found in the commentary about cogito: being and thought.

Keywords: psychoanalysis, graph of the psychoanalytical act, Cartesian cogito, analytical trajectory. 
O presente artigo discute o esquema que fornece a estrutura do ato analítico, explicitando a premissa fundamental que o organiza: a divisão do sujeito entre ser e pensamento. Partimos do pressuposto de que a noção de ato analítico envolve uma leitura particular de Lacan do cogito cartesiano, na medida em que implica um posicionamento do sujeito diante de sua divisão, a qual se dá entre a repetição significante (associada ao pensamento) e o objeto (associado ao ser).

Antes de adentrarmos essa discussão, introduziremos alguns elementos que nos autorizam a dizer que Lacan, em sua reflexão sobre o ato, associa os termos encontrados na filosofia de Descartes - ser e pensamento - a seus conceitos de objeto a e de cadeia significante, respectivamente.

Nos anos que prepararam a teoria do ato analítico, Lacan falou com insistência do sujeito e do ser, afirmando, ao mesmo tempo, que o que ele tecia não era uma ontologia. Nesse período, elaborou uma série de enunciados sobre as relações do sujeito com seu ser, cujo ponto fundamental é que a "falta-a-ser", associada ao desejo, só ganha sentido quando consideramos que o sujeito foi separado de seu ser, em função da castração. E o mais importante a ser assinalado é que Lacan coloca o objeto no lugar do ser perdido pelo sujeito. O que se constata em sua proposição: "o objeto toma o lugar daquilo de que o sujeito foi privado simbolicamente” (LACAN, J. Le désir et son interprétation - Hamlet (Séances du 4 et 11 mars 1959), p. 11. In: Ornicar? N. 26-27. Paris: Navarin, 1959/1981, p. 7-34).

Vê-se, então, que Lacan propõe de modo explícito, que o laço do desejo com o ser deve ser buscado no campo do objeto, o que corrobora a ideia de que a discussão sobre a estrutura do ato analítico, a partir do cogito cartesiano, que põe em cena o sujeito dividido entre ser e pensamento, implica a divisão do sujeito entre o objeto a e a estrutura de linguagem.

Antes de examinarmos o grafo de 1967, organizado a partir do cogito cartesiano, verifiquemos como o mesmo cogito foi interpretado por Lacan alguns anos antes.

\section{AS CONDIÇÕES DA CONSTITUIÇÃO DO SUJEITO E DE FORMALIZAÇÃO DO OBJETO NO SEMINÁRIO XI}

O projeto cartesiano, como se sabe, é o de empreender a reforma do saber e estabelecer alicerces seguros sobre os quais a ciência possa se fundar. Descartes parte do princípio de que nada pode ser conhecido antes da inteligência. Constrói a partir deste ponto um encadeamento de ideias, no qual, as coisas primeiramente propostas devem ser conhecidas sem o auxílio das seguintes; e as seguintes devem ser demonstradas pelas coisas que as precedem. Assim, a filosofia cartesiana tira sua certeza do encadeamento interno das razões, sem recorrer à realidade externa. 
Buscando determinar o primeiro elo da cadeia, o fundamento de sua filosofia, Descartes recusou tudo o que não era absolutamente certo. Criticou os princípios sobre os quais se apoiavam as opiniões correntes e o conhecimento baseado na experiência sensível. Submeteu o conhecimento estabelecido à dúvida, valendo-se da hipótese do gênio enganador. Do processo de radicalização da dúvida Descartes extraiu, no entanto, sua primeira certeza: a condição interna do ato de duvidar. Não posso duvidar sem pensar e não existe pensamento sem existência intelectual. O pensamento é o que surge de inquestionável no cogito; condição última de possibilidade das representações possíveis (GRANGER, 1983, p. XVI).

Lacan apoia-se nesse momento específico do cogito para daí derivar o sujeito da psicanálise. O traço essencial que ele recolhe é a dissociação entre o sujeito e o subjetivo. A certeza do eu penso, como vimos, é adquirida a partir da recusa de todo o conhecimento subjetivo. O sujeito do cogito emerge como resultado do esvaziamento da esfera psíquica de todas as representações qualitativas, como o resíduo que não pode ser eliminado por essa operação. Ainda na perspectiva lacaniana, o que Descartes tira como consequência do cogito não é um saber acerca da natureza daquele que pensa, mas o sujeito que surge como efeito do significante penso. A certeza da existência não assegura identidade ao sujeito que se diz pensante, como constatamos na segunda meditação, na qual Descartes diz: "mas não conheço ainda bastante claramente o que sou, eu que estou certo de que sou” (DESCARTES, 1983 [1637], p. 92).

Esse é um aspecto importante para a dedução de Lacan acerca da discordância entre pensamento e ser, que se depreende do sujeito ao qual nos referimos. Embora o sujeito encontre sua certeza no pensamento, não sabe definir claramente quem é. Neste ponto, experimenta o descentramento em relação ao lugar onde ele obtém sua certeza, por pensar, e é onde Lacan reconhece seu parentesco com a divisão constituinte do sujeito da experiência psicanalítica.

$\mathrm{Na}$ interpretação lacaniana, há na identificação feita no lugar do Outro, lugar do pensamento, uma perda de ser. É o que encontramos no Seminário XI, quando Lacan discute o problema da constituição do sujeito a partir dos termos cartesianos, ser e pensamento, pensando-os no contexto da teoria dos conjuntos (LACAN, Le Séminaire, Livre XI, 1964/73, p. 185). O autor se serve da operação de união para representar a instauração do sujeito pelo significante, e da operação de interseção para mostrar o recobrimento de duas faltas: a primeira situada no campo do Outro, definida como o desejo do Outro, e a segunda, surgida no campo do sujeito, relacionada ao fato de que o sujeito só pode se representar no campo do Outro sob a condição de deixar escapar uma parte de seu ser.

Lacan pensa a constituição do sujeito a partir da relação entre dois conjuntos: o sujeito e o Outro, e das operações alienação e separação, que condenam o sujeito a aparecer sempre dividido (LACAN, Le Séminaire, Livre XI, 1964/73, 
p. 190-191). O recurso de Lacan à teoria dos conjuntos coloca em evidência que, na constituição do sujeito, sempre se produzem fenômenos de perda, pois a instauração do sujeito pelo significante não é total, produzindo sempre um resto. Vejamos agora como o ser, o pensamento, a alienação e a separação são reexaminados por Lacan no esquema do ato analítico do Seminário XV.

\section{SER E PENSAMENTO NO GRUPO DE KLEIN - A ESTRUTURA DO ATO ANALÍTICO}

No referido seminário, Lacan retoma as operações de alienação e separação, apresentadas no Seminário XI, mas de modo diferente. Não mais discute a constituição do sujeito, porém pensa as operações na estrutura do ato analítico, articulado a partir dos termos cartesianos, ser e pensamento, e de um modelo de grupo demonstrado por Félix Klein (LACAN, 1967-68, aula de 24/01/1968).

Ele apresenta à audiência o esquema abaixo, na aula do dia 10 de janeiro de 1968.

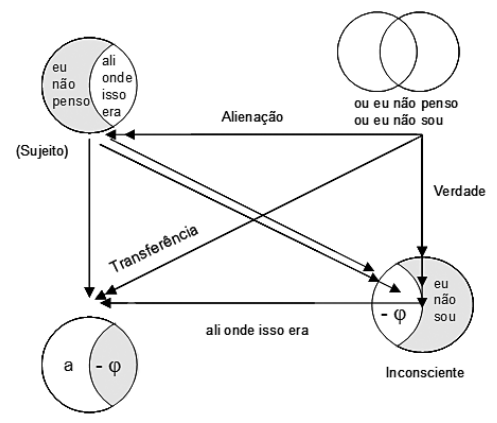

O texto que inspirou Lacan na montagem do esquema é o do matemático francês Marc Barbut, “Sobre o sentido da palavra estrutura nas matemáticas”. Ali, Barbut elege o grupo de Klein para demonstrar o que é uma estrutura nas matemáticas, e ao longo da argumentação fornece uma série de representações que se pode fazer desse grupo. Entre as representações do grupo de Klein oferecidas por Barbut, elegemos a que assume a forma de diagrama (BARBUT, 1996, p. 158), pois é a escolhida por Lacan para montar o grafo do Seminário XV. A representação é a que se segue:

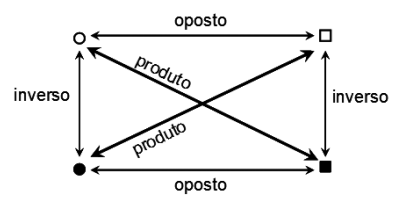

Como se pode observar, acima temos um objeto redondo e branco que tem suas qualidades modificadas: a forma ou a cor. É possível ainda se modificar 
as duas qualidades ao mesmo tempo: a forma e a cor. Existem, então, quatro estados possíveis para o objeto, os quais aparecem ligados por transformações elementares (BARBUT, 1996, p. 154).

Os vetores horizontais indicam a variação da forma e não a da cor. Os verticais indicam, ao contrário, a variação da cor e não da forma. Já os vetores diagonais indicam os dois tipos de variação ao mesmo tempo: a cor e a forma. É possível, então, combinar várias operações, partindo dos quatro cantos do diagrama, aplicando-se a operação oposta, a operação inversa ou a operação produto. A operação oposta é o círculo branco que se transforma em quadrado branco. A operação inversa é o círculo branco que se transforma em círculo negro. A operação produto é resultado das duas operações realizadas consecutivamente e implica o inverso do oposto ou o oposto do inverso.

As operações mencionadas também foram exemplificadas por Barbut com a linguagem dos números. O oposto de um número x é - x (basta trocar o sinal). Já o inverso de um número x é 1/x e o de um número - x é -1/x. A linguagem dos números torna mais evidente a possibilidade de se combinar operações. Tenho um número $\mathrm{x}$, pego seu oposto - $\mathrm{x}$ e depois o inverso de seu oposto $-1 / \mathrm{x}$. Ou então, tomo o inverso de $\mathrm{x}, 1 / \mathrm{x}$, e depois o oposto do inverso, $1 / \mathrm{x}$. As operações apresentadas no grupo são involutivas, fazem retornar à situação precedente. Para encontrar o oposto de um número, basta trocar o sinal (o oposto de $\mathrm{x}$ é - $\mathrm{x}$ ), mas se mudamos o sinal duas vezes consecutivamente, voltamos a x. Da mesma forma, o inverso do inverso também é o número de que se partiu. Vê-se que o percurso indicado pelas flechas pode levar de x a - x (operação oposto) e logo de - x a -1/x (operação inverso), depois de -1/x a 1/x (operação oposto), para, por fim, saindo de $1 / x$, retornar a x (operação oposto). Pode-se percorrer o caminho em várias direções possíveis. O próprio desse diagrama é a característica de voltar sempre ao ponto de partida e a de manter relações lógicas entre os elementos que o compõem, indicadas por flechas que partem em diversas direções.

Essas características levaram Barbut a definir a estrutura do grupo de Klein da forma que se segue: trata-se de "um conjunto onde os elementos são quaisquer, mas entre os quais estão definidas uma ou várias leis de composição” (BARBUT, 1996, p. 152). O matemático ainda acrescenta que esse procedimento só é aplicável a um conjunto finito. Se o conjunto é infinito pode-se dar, no máximo, fragmentos de tabela (idem). Esse aspecto do grupo é importante, porque Lacan usará essa estrutura para esclarecer o percurso da análise, considerada por ele finita, devendo encontrar sua resolução num conjunto finito de elementos.

Obviamente, os elementos do conjunto com os quais Lacan fornece a estrutura do percurso analítico não são elementos quaisquer. Os elementos são o ser, o pensamento, o objeto a e $-\phi$. O interesse de Lacan pelo grupo de Klein, como 
meio de apresentação do percurso analítico, é destacar as relações lógicas entre esses elementos, na experiência da psicanálise, as quais terminam por promover um resultado, um efeito (um produto, nos termos de Barbut).

Ao se apropriar do grupo de Klein, Lacan faz dele um sistema não involutivo. O que significa que, uma vez alcançado o produto, não é possível retornar ao ponto de partida (LACAN, 1967-68, aula de 10/01/1968). Essa é uma ideia propícia para a demonstração do ato analítico e da análise, já que o psicanalista, na perspectiva lacaniana, constitui-se como o produto final de uma análise (LACAN, 1967-68, aula de 07/02/1968), os efeitos de uma análise não sendo dissolvidos depois que ela cessa.

Ao comentar o grafo, Lacan diz que ele é percorrido em certo sentido e que se trata de um mesmo trajeto (LACAN, 1967-68, aula de 17/01/1968), mas isso não significa que todas as setas do grafo indiquem a mesma direção. As setas partem em direções diferentes, indicando múltiplas relações entre as figuras que compõem o esquema. De todo modo, ele rebatiza os vetores que no grupo de Klein são chamados de oposto, inverso, e produto, com os nomes: operação alienação, operação verdade e operação transferência. Determina, também, um ponto de partida para o percurso, além de associá-lo, como já dissemos, ao cogito cartesiano (LACAN, 1967-68, aulas de 10 e 17/01/1968).

\section{O PONTO LÓGICO INICIAL DA ANÁLISE}

O ponto de partida da análise, segundo Lacan, é a figura que se segue:

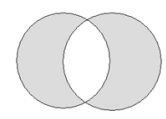

Ou eu não penso ou eu não sou

Ela representa a negação da interseção do cogito cartesiano (interseção entre ser e pensamento) (LACAN, 1967-68, aula de 10/01/1968).

$\mathrm{Na}$ mesma aula, Lacan pergunta como é que se fixa um início (o início do ano, por exemplo) e conclui que é necessário um ato para se localizar um início. A ideia tem relação com o fato de que o ato do psicanalista encontra-se no começo da análise. Ao colocar em marcha o inconsciente, este ato produz como efeito a ruptura do cogito (idem). Provoca a dissociação do sujeito que pensa e do sujeito que é.

Por isso, no ponto lógico inicial da análise, encontramos a disjunção do ser e do pensamento sob a forma de duas frases que estão em uma relação de exclusão: ou não penso ou não sou (idem). 
Desse ponto, partem duas setas para dois conjuntos diferentes. O primeiro dos dois conjuntos é encontrado, no canto superior esquerdo do grafo e o segundo no canto inferior direito. Há duas flechas que partem do primeiro conjunto em direção ao segundo, e que indicam uma relação entre eles.

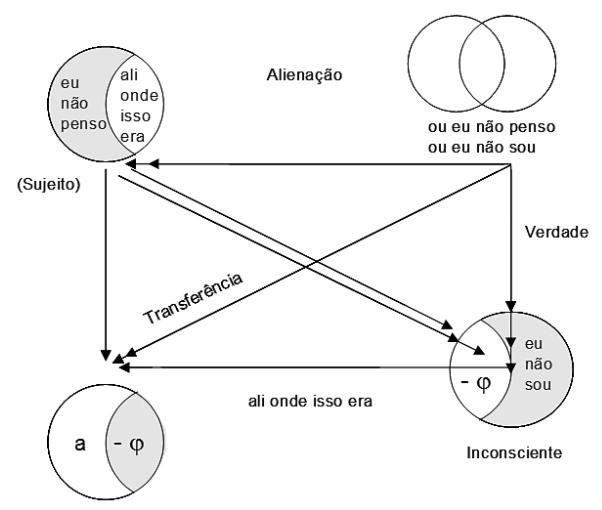

Com a negação da interseção do conjunto do ser e do pensamento, obtém-se, de um lado, o conjunto do ser, com uma zona heterogênea ao ser (ali onde isso era), e que é designado pela frase “eu não penso". E obtém-se, de outro, o conjunto do pensamento, com uma zona heterogênea ao pensamento $(-\phi)$, designada pela frase "eu não sou".

No grupo de Klein, a flecha, que indica a relação entre o elemento situado no canto superior esquerdo e aquele situado no canto inferior direito, indica a operação produto, que combina duas operações realizadas consecutivamente: operação oposto e inverso.

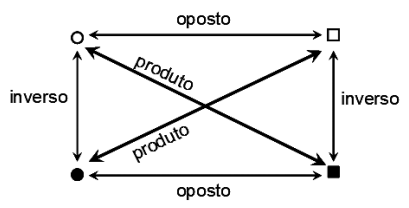

Lacan sugere, então, com seu esquema, que a operação produto, na análise, é a operação transferência, que abrange e articula a operação alienação, na qual o sujeito é e não pensa, e a operação verdade, na qual o sujeito pensa e não é.

A operação alienação é tomada no grafo do ato analítico de maneira distinta da que foi tomada no Seminário XI, na descrição da constituição do sujeito. No Seminário XI, a alienação do sujeito no campo do Outro resultava em uma perda de ser, relacionada ao que permanecia fora da representação do sujeito pelo significante. Já no Seminário XV, a operação alienação confere um ser ao sujeito. Para 
entendermos a diferença, é preciso considerar que Lacan fala da alienação, no Seminário XV, de outro ponto de vista. Ali, ele privilegia o fato de que a alienação na imagem (eu ideal) e nos significantes mestres (ideal do eu) funda as identificações do sujeito conferindo-lhe um ser. Assim, o ser perdido na operação de alienação, no Seminário XI, é o ser relativo ao corpo vivo que escapa à mortificação pela linguagem. Já o ser adquirido pela operação alienação, no Seminário XV, é aquele resultante das identificações imaginárias e simbólicas do sujeito.

Tendo sido esclarecido esse ponto, retomemos o que dizíamos acima: a transferência, no grafo de Lacan, é a operação produto que articula as operações alienação e verdade. É a operação que faz o sujeito passar da posição onde ele é e não pensa (alienação) para a posição onde ele pensa e não é (verdade). A passagem ocorre, quando o analisante, sob transferência, entrega-se ao procedimento da associação livre e já não sabe quem é, em função da vacilação de suas identificações. Ele pode, no entanto, também sob transferência, passar à posição onde é e não pensa. Esse momento da análise foi chamado por Lacan de "fechamento do inconsciente" e foi designado por Freud como o tempo em que o sujeito, no lugar de rememorar, repete com o analista as relações fundamentais com seus objetos. A repetição dá consistência à fantasia e ao ser do sujeito, sustentado por suas identificações alienantes.

É a partir dessa mútua exclusão, proposta por Lacan como o início lógico da análise, que o analisante deve escolher entre o ser, sustentado pelo narcisismo e pelo circuito pulsional da fantasia, e o pensamento inconsciente, do qual está ausente um eu (je) que afirma. E essa é a razão pela qual, deste ponto, partem duas flechas: a que se dirige ao conjunto do pensamento e a outra que se dirige ao conjunto do ser.

Analisaremos agora a operação alienação.

\section{A OPERAC̣ÃO ALIENAC̣ÃO}

O ser promovido pela alienação (identificações do sujeito com seus significantes mestres e eu ideal) é chamado por Lacan, no Seminário XV, de faux être, falso ser (LACAN, 1967-68, aula de 10/01/1968). Encontramos na expressão da língua francesa, um trocadilho que se perde na língua portuguesa. O faux être (falso ser) se confunde com il faut être (é preciso ser). O ponto de vista de Lacan é que, na análise, o sujeito pode modificar sua relação com seus significantes, mas não pode se livrar deles e, nesse sentido, a alienação não é escolha preferencial, mas forçada.

O ser afirmado na operação alienação opõe-se à operação verdade que, segundo Lacan, coloca em questão um penso que comporta um não sou (idem). A posição de alienação opõe-se à operação verdade, própria da experiência da 
análise, porque a afirmação de um ser para o sujeito tem relação estreita com a função de desconhecimento do eu (moi) e com a paixão pela ignorância (LACAN, J. L'instance de la lettre dans l'inconscient ou la raison depuis Freud, 1957, p. 627. In: Écrits. Paris: Éditions du Seuil, 1966). Trata-se do falso ser do narcisismo, fundado num desconhecimento radical, que leva o sujeito a não querer saber nada a respeito da constituição de seu desejo. O falso ser do narcisismo (eu ideal ordenado pelo ideal do eu) é representado no conjunto pela frase não penso e está associado ao isso, circuito pulsional, representado pela frase ali onde isso era.

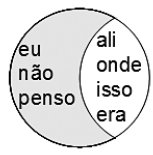

Essa associação pode ser reconhecida na estrutura da fantasia, quando consideramos que o objeto a que ela inclui, de um lado, faz referência a um elemento imaginário, que confere consistência ao eu (moi) e, de outro, faz referência ao circuito pulsional, organizado em torno de um objeto específico. O objeto a da fórmula da fantasia é retirado pelo sujeito do campo do imaginário, para a construção de uma resposta ao enigma do desejo do Outro. E, embora Lacan tenha conferido, mais tarde, o estatuto de real ao objeto a, nunca abandonou a ideia do valor imaginário da fantasia, que sustenta o eu na relação com seus semelhantes.

A associação do falso ser do narcisismo à fantasia também é compreendida quando lembramos que Lacan a situa, no início de seu ensino, como o cenário imaginário situado no eixo a - a', que se interpõe ao inconsciente, eixo $\$$ - A, onde o sujeito é apreendido na cadeia significante. A associação mencionada esclarece, por fim, o que Lacan quer dizer, quando sustenta que optar pelo não penso e reforçar o sou desemboca na afirmação da estrutura gramatical onde está ausente o eu.

O eu a que Lacan se refere, aqui, não é o moi e sim o je. O eu, como instância gramatical, está ausente da frase da fantasia, que organiza um circuito pulsional para o sujeito. Isso é o que Freud mostrou com seu texto "Bate-se em uma criança”, ao reduzir a fantasia a uma fórmula impessoal. O sujeito não aparece na fórmula. Temos simplesmente a apresentação do circuito da pulsão em torno de um objeto, o que indica que no nível da satisfação pulsional não há agente. Ou, se há agente, este é a pulsão acéfala separada do sujeito.

Essa é a perspectiva retomada por Lacan, no Seminário XV, ao afirmar que a pulsão, inscrita na construção fantasística, é a estrutura gramatical onde não se é possível dizer eu. Por essa razão, ele situa, no canto esquerdo superior do grafo, associado à operação de alienação, um conjunto dividido em duas partes: a parte colorida onde ele escreve "não penso" e a parte branca onde ele escreve "ali onde 
isso era". O não penso faz referência ao falso ser afirmado pelo narcisismo, e o ali onde isso era faz referência à fantasia que organiza um circuito pulsional e sustenta imaginariamente o eu no mundo.

A posição de alienação do eu, sustentada pela fantasia, é aquela que o sujeito deve abandonar se quiser envolver-se no processo analítico e alcançar a posição promovida pela operação verdade, representada no esquema abaixo pelo conjunto do pensamento, com uma parte que contém um elemento que representa a castração imaginária.

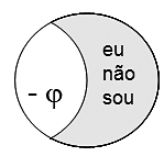

\section{A OPERAÇÃO VERDADE}

O pensamento instaurado pela operação verdade é o pensamento inconsciente, desencadeado pela associação livre. Está relacionado a um não sou, porque quando o sujeito se põe a pensar dessa maneira já não sabe quem é. O falso ser do narcisismo desmorona. A escolha pelo pensamento em detrimento do ser é a escolha do analisante pelo inconsciente, a qual implica a perda das certezas identificatórias, e faz o sujeito surgir como falta-a-ser (LACAN, 1967-68, aula de $07 / 02 / 1968)$.

Não devemos, no entanto, tomar a passagem da operação alienação à operação verdade numa espécie de sucessão temporal, como se primeiro o sujeito chegasse em análise com seu falso ser, depois fizesse a escolha pelo pensamento, perdendo suas certezas identificatórias, para, em seguida, em função da operação transferência, alcançar o ponto equivalente ao final de análise.

Assinalamos acima, que no grafo havia flechas indicando diferentes direções e relações, e que esse fato contrariava toda leitura que pretendesse inseri-lo numa perspectiva de sucessão temporal linear, tornando sua leitura mais complexa. Logo, a interpretação mais rica é considerar que as setas que partem do ponto lógico ou não penso ou não sou, e que indicam a operação alienação e a operação verdade, apresentam o que Lacan chamou de batimento do inconsciente. As setas mostram os momentos de fechamento e abertura do inconsciente, que ocorrem ao longo da análise. Aí, o analisante alterna a posição de alienação, que dá consistência a seu falso ser, e a posição verdade, relativa aos efeitos de verdade promovidos pelas interpretações.

Assim, as relações entre as operações alienação e verdade devem ser tomadas em seu sentido lógico e não cronológico. Esse aspecto é o que faz Lacan dizer que o mais verdadeiro do sujeito aparece na operação alienação como o objeto a, representado, no conjunto do canto superior esquerdo, com a frase "ali onde 
isso era". Já na operação verdade, o objeto a aparece como falta $(-\phi)$. A falta é o fundamento do desejo, produz o efeito falta-a-ser e, no final da análise, emerge sob a forma do confronto do sujeito com a castração (LACAN, 1967-68, aula de 10/01/1968).

A perspectiva de Lacan é a de que o que aparece como perda num lugar, aparece como falta em outro (idem). A perda do objeto $a$, inerente à operação alienação, surge na operação verdade como castração (objeto que falta), não numa sequência cronológica, mas como correlação coerente. E a transferência é o operador que articula a alienação do sujeito, que determina a perda do objeto a e o processo de apreensão da verdade do sujeito, onde a perda do objeto re-surge como falta.

Como é possível constatar no grafo, a perda, na operação de alienação, é apresentada no conjunto do canto superior esquerdo com a frase ali onde isso era e re-surge na operação verdade, apresentada como $-\phi$ no canto inferior direito.

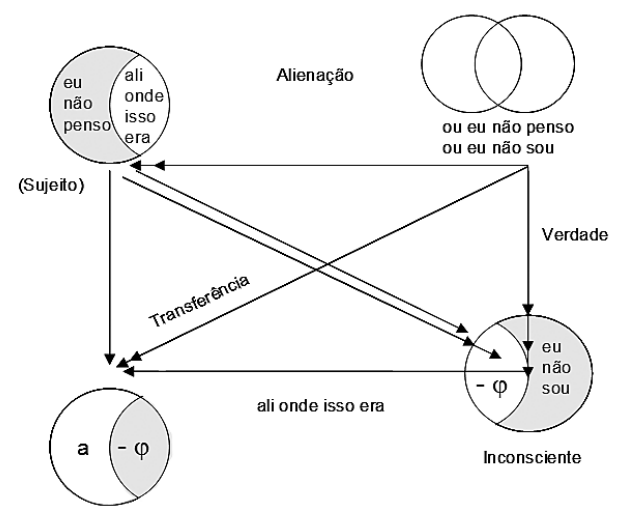

A operação verdade transforma a perda de sentido e de ser em falta (falta-a-ser), pois, de acordo com Lacan, a condição para que haja ato analítico é o engajamento do sujeito num tipo de pensamento que comporta um não sou e que vai conduzi-lo ao encontro da castração (idem).

\section{A OPERAÇÃO TRANSFERÊNCIA}

A outra operação analítica apontada por Lacan é a operação transferência, com a qual ele tenta responder como é que, em uma análise, termina-se com a falta-a-ser. Ele responde dizendo que se termina com a falta-a-ser com a afirmação de um sou, que combina o objeto a (o ser) e o $-\phi$ (o pensamento). Por isso, Lacan situa a transferência no mesmo eixo que, no grupo de Klein, está situada a operação produto, a qual combina as operações oposto e inverso. A transfe- 
rência combina o resultado da operação alienação (a perda do objeto a, perda de ser) e o resultado da operação verdade (a perda do objeto transformada em falta), produzindo, no final do percurso da análise, no canto inferior esquerdo do grafo, um conjunto dividido em duas partes. Na primeira, Lacan escreve a e, na segunda, escreve $-\phi$.

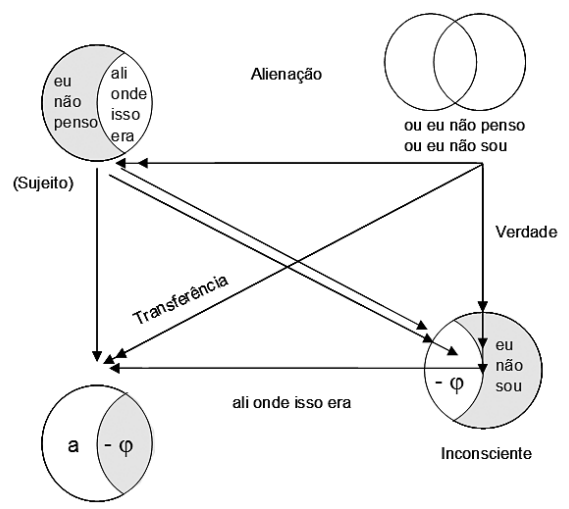

Por isso, no esquema apresentado no Seminário XV, a operação transferência parte do ou não penso ou não sou (relação de exclusão entre ser e pensamento) e chega ao conjunto que combina o ser (o objeto a) e o pensamento (- $\phi$ ). Lacan quer mostrar que o ato analítico opera no eixo da transferência, incidindo sobre a articulação lógica entre a perda do objeto, referida à operação alienação e a castração (perda transmutada em falta), referida à operação verdade, provocando algum tipo de resolução. $\mathrm{O}$ ato analítico opera, na transferência, incidindo sobre a divisão do sujeito entre o ser (a) e o pensamento (- $\phi)$, promovendo uma saída para essa divisão. Para Lacan, a divisão do sujeito é a condição prévia ao ato analítico (LACAN, 1967-68, aula de 25/01/1968) e o objeto a é o resultado da cisão que o sujeito sofre pela ação de castração pelo significante (LACAN, J. Subversion du sujet et la dialectique du désir dans l'inconscient freudien, 1960, p. 815, 816. In: Écrits. Paris: Éditions du Seuil,1966).

Sob este ponto de vista, algumas leituras podem ser feitas sobre o ato analítico. Uma delas é dizer que o ato incide sobre a divisão do sujeito, provocada em razão da castração, promovendo, com sua incidência, um tratamento dessa divisão. Outra é dizer que o ato opera de modo distinto da interpretação de sentido. O agente do ato é o objeto a, e seu efeito é a suspensão momentânea do pensamento. O ato separa, por um instante, o objeto a e o pensamento e, assim, reedita a divisão estrutural do sujeito.

Como veremos adiante, o produto da operação transferência - do ato analítico - é a separação de - $\phi$ e de a. Essa ideia é consoante com a perspectiva da 
separação apresentada em 1964, quando Lacan diz que a separação tem a função de limite, mas também, a função de torção na qual reconhecemos a Ichspaltung (a divisão do sujeito). E também, quando faz equivaler a palavra separar (séparer) ao termo se parere, que ele define como "engendrar a si mesmo (LACAN, J. Posicion de l'inconscient, 1964. In: Écrits. Paris: Éditions du Seuil, 1966, p. 842, 843).

No grafo do ato analítico, a separação do objeto a da dimensão imaginária da castração, situada pela fantasia, é o que permite ao sujeito perceber que o objeto a, causa de seu desejo, é o que conferia consistência a sua resposta ao enigma do desejo do Outro. É o que possibilita que o sujeito em análise seja engendrado de forma inédita.

Tal separação acontece na dimensão da transferência. Segundo Lacan, o ato analítico está intimamente ligado à transferência, não existindo fora dessa dimensão (LACAN, 1967-68, aula de 29/11/1968). A operação transferência, no grafo do ato analítico, parte do início lógico da análise ou não penso ou não sou para chegar ao seu resultado final. O grafo mostra que a transferência é o eixo do tratamento analítico. Ela está no seu início, quando liga o analisante ao analista pela via de suposição de saber e pela via do amor. Está presente ao longo de seu desenvolvimento, quando promove a elaboração de saber relativa ao sintoma e à fantasia, e quando aparece sob a forma da repetição e da resistência. Por último, ela está em seu final, o qual depende da resolução da transferência e da subversão do sujeito suposto saber.

A transferência, na elaboração lacaniana, comporta dupla vertente: a do saber e a do objeto. A pergunta sobre o significado do sintoma é o que instaura, na análise, a função do sujeito suposto saber. Por outro lado, a transferência faz surgir o amor e seus fenômenos e, paradoxalmente, acaba por se tornar uma das fontes de maior resistência à associação livre.

A concepção da transferência em sua dupla vertente é importante para entender a relação do ato analítico com a subversão do sujeito suposto saber e com a destituição subjetiva, no final de análise. Pode-se reconhecer essa dupla vertente no comentário de Lacan sobre a liquidação da transferência, quando ele diz que o ser do desejo e o ser do saber se enlaçam numa banda, feita com uma só borda, onde se inscreve uma só falta (LACAN, J. Proposition du 9 octobre 1967 sur le psychanalyste de l'École, 1967, p. 254. In: Autres Écrits. Paris: Éditions du Seuil, 2001) e que a transferência é o pivô dessa alternância (idem). O autor retoma, nesse comentário, a ideia do recobrimento das duas faltas, na operação de separação, apresentada no Seminário XI. A primeira situada no campo do Outro, falta no campo do saber, e a segunda no campo do sujeito, falta no campo do desejo, relacionada ao objeto a, causa do desejo. E retoma, também, a perspectiva que destacamos acima, ou seja, a de que o objeto a que aparece como perda na 
operação alienação, reaparece como falta na operação verdade, e que a perda e a falta são articuladas logicamente na operação transferência.

Sob o ponto de vista de Lacan, as operações de alienação e separação esboçam duas dimensões que se articulam: o Outro (campo onde inscrevemos o saber, o sentido, o pensamento) e o sujeito (campo onde inscrevemos o desejo, o ser, o objeto a). No Seminário XI, essas operações se articulam na teoria dos conjuntos e dizem respeito à constituição do sujeito. Mas, em 1967, Lacan sugere que elas se articulam numa figura da topologia, a banda de Moebius (banda feita com uma só borda), e estão implicadas no ato do analista produzido na transferência. O desejo ocasionado pela falta do objeto a (relativo ao sujeito) e o saber no qual falta um significante (relativo ao Outro), como vimos acima, estão numa única e mesma face, e é por isso que Lacan diz que a falta no campo do saber faz uma com a falta no campo do desejo.

O que Lacan coloca em questão com a operação transferência, no esquema do ato que analisamos, é que esse último incide na neurose de transferência, promovendo um re-ordenamento das relações de suas duas vertentes: a do saber e a do objeto. A perspectiva de Lacan aproxima-se da de Freud que sustentou que, na experiência analítica, para além da decifração de sentido promovida pela interpretação, subsiste um resto inanalisável, chamado por ele de "complexo de castração" (FREUD, 1937/1996, p. 268). Freud e Lacan, cada um a seu modo, constataram que a interpretação é uma operação de saber que encontra seu limite no fato de que o gozo não é mensagem, não podendo, por essa razão, ser interpretado. Lacan chama o gozo residual, que permanece à margem da operação de saber, de objeto a.

O ato analítico, segundo Lacan, é a intervenção do analista que opera uma mudança, na transferência, no nível do sujeito suposto saber (LACAN, 196768, aula de 10/01/1968), reorganizando as relações entre o saber e o objeto. O conjunto apresentado por Lacan, no canto inferior esquerdo do esquema, como produto da operação transferência, sugere que com o ato alcança-se uma saída que combina a causa do desejo e o saber. Ou podemos recorrer aos termos cartesianos para dizer que o ato analítico é a intervenção que, no final de análise, promove uma saída que combina ser e pensamento.

Recebido em: 8 de fevereiro de 2012. Aprovado em: 10 de outubro de 2012. 


\title{
BIBLIOGRAFIA
}

BARBUT, M. Sobre o sentido da palavra estrutura nas matemáticas. In: . O ato analítico. Revista da Letra Freudiana. Ano XV, n. 16. Rio de Janeiro: Revinter, 1996. P. 145-167.

DESCARTES, R. Meditações: Discurso do Método. São Paulo: Abril Cultural, 1983, p. 75-149. Os pensadores.

FREUD, S. Obras completas. Ed. standard brasileira. Rio de Janeiro: Imago, 1996. Análise terminável e interminável.

GRANGER, G-G. Vida e obra. In: Descartes. São Paulo: Abril Cultural, 1983, p. VII-XX. Os pensadores.

LACAN, J. Le Séminaire. L'acte psychanalytique (inédito). 1968. V. 15.

. Le Séminaire. Le désir et son interprétation - Hamlet (Séances du 4 et 11 mars 1959). In: Ornicar? N. 26-27. Paris: Navarin, 1981, p. 7-34.

Le Séminaire. Les quatre concepts fondamentaux de la psychanalyse. 1973. V. 11.

L'instance de la lettre dans l'inconscient ou la raison depuis Freud. In: Écrits. Paris: Seuil, 1966.

Posicion de l'inconscient. In:__. Écrits. Paris: Seuil, 1966. Proposition du 9 octobre 1967 sur le psychanalyste de l'École. In: . Autres Écrits. Paris: Seuil, 2001.

. Subversion du sujet et la dialectique du désir dans l'inconscient freudien. In: Écrits. Paris: Seuil, 1966.

\author{
Mônica Assunção Costa Lima \\ aclimamonica@gmail.com
}


